\title{
Female versus male migraine: an event-related potential study of visual neurocognitive processing
}

\author{
Yunliang Guo 1,2, Song Xu' ${ }^{1,2}$, Shanjing Nie ${ }^{1,2}$, Mimi Han ${ }^{1,2}$, Yue Zhang ${ }^{1,2}$, Jian Chen ${ }^{1,2}$, Xunyao Hou ${ }^{1,2}$,
} Yan Hong ${ }^{1,2}$ and Xueping Liu ${ }^{1,2,3^{*}}$ (D)

\begin{abstract}
Background: Several studies have suggested cognitive deficits in migraineurs, and sex differences have also been observed in migraine, such as a higher prevalence in females. Nevertheless, little is known about gender-related differences in cognitive processing. In this study, we aimed to investigate the effect of gender on neurocognitive processing in migraineurs.

Methods: Altogether, 46 migraine patients without aura (23 females; mean age 32.848 years) during the interictal period and 46 age-matched healthy controls (23 females; mean age 32.652 years) were recruited. The emotional characteristics of participants were evaluated, and attentive processing was analyzed via event-related potential examinations using a three-stimulus visual oddball paradigm.

Results: We found that migraineurs suffered from emotional and visual cognitive processing abnormalities compared with healthy controls, including higher levels of anxiety and reduced P3 amplitude. These parameters were modulated by gender in migraine patients, but not in healthy participants. Our findings indicated that female patients seemed to be more anxious and have more severe impairment in attentive processing of visual stimuli than their male counterparts. The gender-related differences in migraineurs were further validated using eventrelated potential difference waveforms.

Conclusions: These results suggested that migraine might have an additional influence on females and lead to more dysfunction in their interictal neurocognitive processing. Our findings provide evidence that a gender effect exists in migraineurs, which should be considered when designing experiments and exploring treatment approaches. The gender-related differences and underlying mechanisms deserve further investigation for patients with migraine.
\end{abstract}

Keywords: Migraine, Gender-related differences, Event-related potential, P3, Attentive visual processing

\section{Background}

Migraine is a debilitating pain disorder, characterized by severe throbbing headaches, photophobia, phonophobia and gastrointestinal disturbances, which causes lower quality of life, impaired sociability, loss productivity and even disability [1]. Psychiatric disorders, such as anxiety and depression, are common comorbidities of migraine

\footnotetext{
* Correspondence: Liuxueping1962@163.com

'Department of Senile Neurology, Shandong Provincial Hospital Affiliated to Shandong University, Jinan 250021, Shandong, People's Republic of China ${ }^{2}$ Anti-Aging Monitoring Laboratory, Shandong Provincial Hospital Affiliated to Shandong University, Jinan 250021, Shandong, People's Republic of China Full list of author information is available at the end of the article
}

[2], and patients with chronic migraine often exhibit affective temperamental dysregulation and suicidal behaviors as well [3]. These specific psychological characteristics may significantly contribute to the psychosocial impairment and negatively modify the outcomes of migraineurs. In addition, some studies have indicated that migraineurs could suffer from cognitive deficits in several domains [4, 5] or subsequent dementia [6]. Migraine is closely associated with an increased prevalence of gray matter volume reduction in frontal cortex and cingulate gyrus, deep white matter lesions and

(c) The Author(s). 2019 Open Access This article is distributed under the terms of the Creative Commons Attribution 4.0 International License (http://creativecommons.org/licenses/by/4.0/), which permits unrestricted use, distribution, and reproduction in any medium, provided you give appropriate credit to the original author(s) and the source, provide a link to the Creative Commons license, and indicate if changes were made. 
subclinical cerebral infarcts as well $[7,8]$, which can all lead to cognitive decline [9].

Interestingly, there have been evidence indicating the existence of gender differences in migraine, including: 1) the prevalence is about twice as high in females compared with males [10], 2) most associated symptoms are more prevalent and severe in women [11], 3) female migraineurs have a greater number of comorbid diseases and are more likely to suffer from psychiatric comorbidities [12, 13], 4) higher headache-related disability and healthcare resource utilization in females [14], 5) gender-related responses to anti-migraine treatments such as triptans [15], 6) the potential influence of estrogen fluctuations in female migraineurs [16], and 7) sex differences in structural and functional brain alterations $[17,18]$. Moreover, gender is also an important influential element in cognitive-behavioral performance $[19,20]$. Nevertheless, to date, there has been little discussion on cognitive differences between male and female patients with migraine. Owing to difference in the incidence of this disease, there is the high possibility that migraine might exert diverse effects on cognitive processing between males and females.

Event-related potential (ERP) is a relatively objective and noninvasive neurophysiological examination that can reflect underlying brain activities during cognitive processing, and has been increasingly employed as a cognitive marker in various neurological disorders. P3 (also called P300), the most investigated ERP component, is regarded as an effective index of cerebral information processing [21].

The aim of the present study was to characterize the effect of gender on migraine and possible interactions between gender and the disease in neurocognitive processing using a modified visual oddball paradigm. We hypothesized that migraineurs overall suffered from attentive processing impairment and attentional ERP abnormalities, such as reduced P3 amplitude and/or prolonged P3 latency. More importantly, considering the reported gender-related discrepancies in associated symptoms, comorbidities, headache-related disability and cerebral dysfunction $[11,13,14,17]$, the impairment severity might also not be the same between male and female migraineurs. The attentive visual processing in migraine sufferers, assessed by corresponding original/ difference ERP components, might map onto observed gender-related functional differences.

\section{Methods}

\section{Participants and criteria}

Altogether, we recruited 49 outpatients with migraine without aura (25 females) from Shandong Provincial Hospital Affiliated to Shandong University. Besides, 48 age-matched healthy controls (24 females) recruited from hospital/ laboratory staff participated in this study. They did not suffer from any recurrent headache or drug/alcohol abuse.

All patients underwent necessary neurological examinations by two specialized neurologists (XL and $\mathrm{XH}$ ), and were diagnosed according to the beta version of the International Classification of Headache Disorders, 3rd edition (ICHD-3 beta). Migraineurs were in the interictal period when enrolled, and had no attack $72 \mathrm{~h}$ prior to the recording and no symptoms of developing a migraine during or $72 \mathrm{~h}$ after the recording. The inclusion criteria for patients were: 1) fulfilling the criteria for migraine without aura as classified in the ICHD-3 beta, 2) aged between 18 and 45 years, 3) at least one migraine episode per month and at least 1 year's migraine history, and 4) outside migraine attacks during the recording, as well as at least $72 \mathrm{~h}$ before and after the experiment. The exclusion criteria for patients were: 1) receiving prophylactic anti-migraine therapy, 2) a history of analgesic drug overuse or addiction, 3) a drug/substance abuse or dependency, 4) general neurological disorders, 5) a history of mixed headache types, and 6) abnormal findings on neurological examinations or brain morphology indicating other potential neurological diseases. We also excluded participants who were illiterate, vision impaired, suffering from depression, or having suicide ideation and/or previous suicide attempts. All female subjects were verified to take no oral contraceptives for at least 1 week.

Within the study, migraine characteristics were obtained by a standardized interview using a structured questionnaire, including: 1) the frequency and duration of attacks during the previous year, 2) the history of migraine, and 3) the headache score representing a rating of the most severe migraine suffered over the past year by visual analog scale (VAS), with 0 indicating no pain and 10 worst possible pain respectively.

Furthermore, 3 migraineurs ( 2 females) were excluded - two for excessive artefacts (blink and electromyographic activity) within electroencephalogram (EEG) data and one for incomplete clinical characteristics. So 46 patients ( 23 females) in total were included. In terms of controls, 2 participants ( 1 female) had to be excluded. One for lack of emotional rating scales and the other for technical problems during recording. Thus, we finally included 46 controls ( 23 females) for further analysis.

\section{Emotional evaluation}

In this study, we used Self-Rating Anxiety Scale (SAS) and Self-Rating Depression Scale (SDS) to evaluate emotional state of subjects as described in our previous study [22]. In brief, all participants responded to a series of questions associated with daily life to determine whether they had emotional abnormalities and severity. 
Each scale contains 20 items rated on a four-level Likert scale, ranging from "never occurring or just a little of the time" to "most of the time" [23, 24]. Responses were summed to obtain a total score, and higher scores suggested greater levels of anxiety or depression symptomatology. The anxiety or depression state was defined as score of SAS above 49 or score of SDS above 52, respectively.

\section{Stimuli and procedure}

All subjects were seated comfortably in an armchair in an electrical shielded and sound attenuated chamber, and were directed to fixate and attend to a fixation cross at the center of a screen (23 in.) situated $0.5 \mathrm{~m}$ in front of them. A modified visual oddball paradigm was applied, and 501 stimuli divided into three separate blocks were presented in a random fashion with each stimulus lasting for $400 \mathrm{~ms}$ and a fixed inter-stimulus interval of $400 \mathrm{~ms}$. Stimuli were comprised of standard (smaller circle, $n=381, p=0.76$ ), target (larger circle, $n$ $=60, p=0.12$ ) and novel (square, $n=60, p=0.12$ ) stimuli. During the experiment, participants were instructed to discriminate target stimuli ( $n=60,20$ for every block) from other stimuli as accurately and quickly as possible, and were required to count the number of target stimuli presented in each block mentally. Thereafter, the number was reported, followed by calculation and recording of accuracy based on counting mistakes. Subjects with accuracy below $90 \%$ were not considered in data analysis.

\section{Recording of EEG signals}

The continuous EEG signals (sampling rate $1000 \mathrm{~Hz}$, low pass filter $100 \mathrm{~Hz}$ ) were obtained from midline $\mathrm{Fz}$, $\mathrm{Cz}$ and $\mathrm{Pz}$ electrode sites in accordance with the 10-20 international system using Neurolab EEG/ERPs 32 Channel Amplifier. All scalp electrodes were referenced to left mastoid signals, with right mastoid as ordinary recording site. Electrooculogram (EOG) was recorded with electrodes placed above and below the right eye and $10 \mathrm{~mm}$ from the outer canthi. Electrode impedance was maintained below $5 \mathrm{k} \Omega$ throughout the experiment.

\section{EEG data analysis and measurement}

ASA 4.9.3 software was used for off-line analysis of EEG data. The data were re-referenced to the average of bi-mastoid signals. EOG artifacts were removed using independent component analysis (ICA) as suggested by Jung et al. [25], followed by bandpass filtering at 0.1-30 $\mathrm{Hz}$ (24 dB/octave). Afterwards, EEG signals obtained were segmented into the epoch from $200 \mathrm{~ms}$ pre-stimulus to $800 \mathrm{~ms}$ post-stimulus, and $\mathrm{a}-200$ to $0 \mathrm{~ms}$ pre-stimulus baseline was applied for all ERP waveform corrections. Trials contaminated by high-frequency noise, other extra-cerebral artifacts, or peak-to-peak deflection exceeding $\pm 100 \mu \mathrm{V}$ amplitude at any electrode were automatically excluded from averaging. The segments were averaged separately for standard, target and novel stimuli, and grand averaged waveforms were generated using single-subject waveforms for further analysis.

The peak amplitudes and latencies of original ERP components were measured relative to the pre-stimulus baseline period. The positive peak between 300 and $500 \mathrm{~ms}$ post-stimulus, the negative peak between 50 and $190 \mathrm{~ms}$, the positive peak between 110 and 270 $\mathrm{ms}$, and the negative peak between 210 and $370 \mathrm{~ms}$ were applied to define the P3, N1, P2 and N2 components, respectively (Fig. 1).

To reliably observe and better assess the target and novel effects, the difference waveforms were obtained by subtracting ERPs in response to standard stimuli from those in response to target and novel stimuli, respectively, and the components which showed significant gender difference in migraine patients were further analyzed at corresponding time intervals in difference waveforms (see Fig. 3).

The experimenters were blind regarding the subject's diagnosis and gender throughout preprocessing and measurements of EEG data.

\section{Statistical analysis}

Quantitative data were presented as mean \pm standard deviation (SD). To compare demographic features, emotional characteristics and behavioral parameters, a two-way analysis of variance (ANOVA) was conducted. Student's $t$-test for independent samples (two-tailed) was used for comparisons of clinical features between male and female patients. Additionally, amplitudes and latencies of original ERP components were analyzed by repeated-measures ANOVA, with stimulus (standard, target and novel) and electrode $(\mathrm{Fz}, \mathrm{Cz}$ and $\mathrm{Pz})$ as within-subject factors, while with group (migraineurs vs. healthy controls) and gender (male vs. female) as between-subject factors. For difference ERP components, repeated-measures ANOVA was performed with electrode $(\mathrm{Fz}, \mathrm{Cz}$ and $\mathrm{Pz})$ as a within-subject factor, while with group (migraineurs vs. healthy controls) and gender (male vs. female) as between-subject factors. The degrees of freedom were corrected for nonsphericity using Greenhouse-Geisser epsilon if necessary. Further post-hoc analysis using Bonferroni correction was conducted for significant results. Statistical calculations were carried out with SPSS 23.0 (SPSS Inc., Chicago, IL, USA). The significance level was fixed at 0.05 for all analyses, and effect sizes were reported as partial eta squared $\left(\eta^{2}\right)$. 


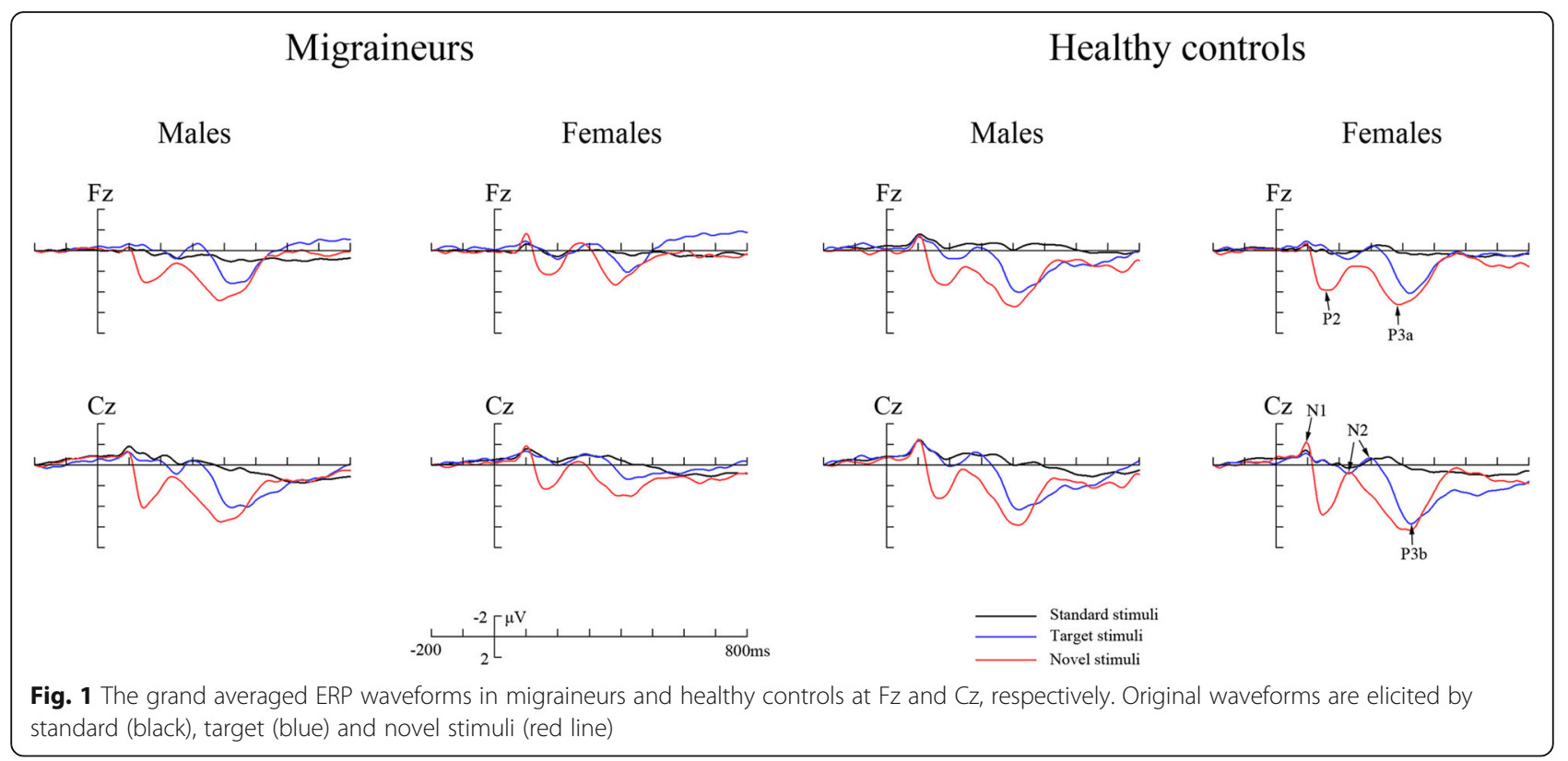

\section{Results}

\section{Subject characteristics}

Tables 1 and 2 show demographic and clinical characteristics. We did not find effects or interactions in age and education level of participants $(p s>0.3)$. There existed no significant sex differences in migraine frequency $(p$ $=0.763)$, duration of attacks $(p=0.897)$, history of migraine $(p=0.798)$ and headache score $(p=0.658)$ either.

\section{Emotional features}

The emotional evaluation indicated that migraine patients were more anxious than healthy controls $(F(1,88)$ $=23.814, p<0.001$, partial $\left.\eta^{2}=0.213\right)$, while across groups, SAS score was not affected by gender $(F(1,88)=$ $2.462, p=0.120)$. We found significant group $\times$ gender interaction $(F(1,88)=4.004, p=0.048)$, and both male

\section{Table 1 Subject characteristics}

\begin{tabular}{lll}
\hline & Migraineurs & Healthy controls \\
\hline $\mathrm{N}$ & 46 & 46 \\
Age, years & $32.848 \pm 6.467$ & $32.652 \pm 6.360$ \\
Age range, years & $20-45$ & $21-45$ \\
Education, years & $13.565 \pm 2.802$ & $14.022 \pm 4.726$ \\
Migraine frequency, times per month & $3.783 \pm 2.890$ & - \\
Duration of migraine, hours & $20.696 \pm 20.069-$ & - \\
History of migraine, years & $7.630 \pm 5.097$ & - \\
Headache score, 0-10 & $5.457 \pm 0.982$ & - \\
SAS score & $42.913 \pm 8.453$ & $35.543 \pm 6.217$ \\
SDS score & $40.043 \pm 9.716$ & $36.522 \pm 7.580$ \\
\hline
\end{tabular}

Data were expressed as mean \pm SD

SAS Self-Rating Anxiety Scale, SDS Self-Rating Depression Scale and female migraineurs tended to be more anxious than their control counterparts $(F(1,88)=4.144, p=0.045$ for males and $F(1,88)=23.674, p<0.001$ for females $)$. In addition, the SAS score was higher in female patients compared with male patients $(F(1,88)=6.373, p=$ $0.013)$, but not for healthy participants $(F(1,88)=$ 0.093, $p=0.761$ ) (see Table 2).

No group, gender effects or group $\times$ gender interaction was obtained in SDS score ( $p s>0.05)$.

\section{Behavioral data}

For accuracy of subjects (male migraineurs, 97.2\%; female migraineurs, 97.1\%; male controls, 97.6\%; female controls, 97.9\%), no effects or interaction was observed significant $(p s>0.2)$.

\section{Original ERP analysis}

The grand averaged ERP waveforms are demonstrated in Fig. 1, and analyses of multiple original ERP components are summarized in Table 3.

\section{P3 component}

Figure 2a depicts topographies of voltage distribution for P3b and P3a components. P3 amplitude showed remarkable main effect of stimulus $(F(1.722,151.528)=113.387$, $p<0.001$, partial $\left.\eta^{2}=0.563\right)$, with a maximum of $5.790 \mu \mathrm{V}$ (SD 3.458) for novel stimulus (P3a). The amplitude was markedly reduced in migraine patients (3.584 $\pm 3.112 \mu \mathrm{V})$ compared with healthy controls (4.681 \pm $3.776 \mu \mathrm{V}, p=0.001$, partial $\left.\eta^{2}=0.125\right)$. Although no difference was found between genders $(p=0.105)$, the interaction of group $\times$ gender was statistically significant $\left(p=0.002\right.$, partial $\left.\eta^{2}=0.100\right)$ (Table 3$)$. Post-hoc analysis 
Table 2 Subject characteristics

\begin{tabular}{|c|c|c|c|c|}
\hline & \multicolumn{2}{|l|}{ Migraineurs } & \multicolumn{2}{|l|}{ Healthy controls } \\
\hline & Males & Females & Males & Females \\
\hline N & 23 & 23 & 23 & 23 \\
\hline Age, years & $32.957 \pm 6.335$ & $32.739 \pm 6.737$ & $32.870 \pm 5.802$ & $32.435 \pm 6.999$ \\
\hline Age range, years & $21-43$ & $20-45$ & $21-45$ & $22-45$ \\
\hline Education, years & $13.217 \pm 2.923$ & $13.913 \pm 2.695$ & $13.652 \pm 4.052$ & $14.391 \pm 5.383$ \\
\hline Migraine frequency, times per month & $3.652 \pm 3.024$ & $3.913 \pm 2.811$ & - & - \\
\hline Duration of migraine, hours & $20.304 \pm 20.195$ & $21.087 \pm 20.387$ & - & - \\
\hline History of migraine, years & $7.435 \pm 4.143$ & $7.826 \pm 5.992$ & - & - \\
\hline Headache score, 0-10 & $5.391 \pm 0.941$ & $5.522 \pm 1.039$ & - & - \\
\hline SAS score & $40.217 \pm 7.323$ & $45.609 \pm 8.794$ & $35.870 \pm 6.398$ & $35.217 \pm 6.157$ \\
\hline SDS score & $39.000 \pm 9.313$ & $41.087 \pm 10.202$ & $36.130 \pm 7.092$ & $36.913 \pm 8.179$ \\
\hline
\end{tabular}

Data were expressed as mean \pm SD

SAS Self-Rating Anxiety Scale, SDS Self-Rating Depression Scale

revealed no noteworthy difference between male migraineurs and male controls $(F(1,88)=0.089, p=0.767)$, but for females, the amplitude was lower in migraineurs $\left(F(1,88)=22.232, p<0.001\right.$, partial $\left.\eta^{2}=0.202\right)$. Furthermore, P3 amplitude was not modulated by gender in controls $(F(1,88)=1.103, p=0.297)$, while in patients, it was larger for males than for females $(F(1,88)=11.338$, $p=0.001$, partial $\eta^{2}=0.114$ ) (Fig. 2a).

As for P3 latency, remarkable main effect of stimulus $\left(F(1.975,173.800)=12.386, p<0.001\right.$, partial $\left.\eta^{2}=0.123\right)$ was obtained, of which novel-elicited P3a was fastest $(398.830 \pm 38.123 \mathrm{~ms})$. The analysis did not verify other significant results $(p s>0.2)$.

\section{N1 component}

Although neither group $(p=0.310)$ nor gender effects $(p=0.813)$ was found significant in N1 amplitude, there existed a noticeable interaction of group $\times$ gender $(p=$ 0.038). Further post-hoc tests indicated that in males, the amplitude was smaller for migraineurs than for controls $(F(1,88)=4.887, p=0.030)$, while not in females $(F(1,88)=0.588, p=0.445) . \mathrm{N} 1$ amplitude was not affected by gender in both groups ( $p s>0.05)$.

No significant difference was discovered in analysis of N1 latency $(p s>0.1)$.

\section{P2 component}

In terms of P2 amplitude, significant stimulus effect $\left(F(1.277,112.348)=113.309, p<0.001\right.$, partial $\eta^{2}=$ $0.563)$ was obtained, and novel stimulus elicited the largest amplitude $(4.340 \pm 2.728 \mu \mathrm{V})$. As shown in Table 3, the group $(p=0.085)$ and gender effects $(p=0.297)$ did not reach significant levels, while there appeared to be noticeable group $\times$ gender interaction $(p=0.001$, partial $\eta^{2}=0.116$ ). Subsequent analysis displayed that in females, the amplitude was reduced in migraineurs compared with controls $(F(1,88)=13.201, p<0.001$, partial $\eta^{2}=0.130$ ), but this phenomenon did not exist in males $(F(1,88)=1.360, p=0.247)$. No difference was observed between male controls and female controls

Table 3 Results and analyses of original ERP components

\begin{tabular}{|c|c|c|c|c|c|c|c|c|}
\hline \multirow[b]{2}{*}{ Original ERPs } & & \multicolumn{2}{|l|}{ Migraineurs } & \multicolumn{2}{|l|}{ Healthy controls } & \multicolumn{3}{|l|}{ Statistics } \\
\hline & & Males & Females & Males & Females & $\begin{array}{l}\text { Group } \\
F(1,88)\end{array}$ & $\begin{array}{l}\text { Gender } \\
F(1,88)\end{array}$ & $\begin{array}{l}\text { Group } \times \text { Gender } \\
F(1,88)\end{array}$ \\
\hline \multirow[t]{2}{*}{ P3 } & Amplitude $(\mu \mathrm{V})$ & $4.321 \pm 3.390$ & $2.848 \pm 2.613$ & $4.451 \pm 3.504$ & $4.911 \pm 4.025$ & $12.564^{* *}$ & 2.684 & $9.757^{* *}$ \\
\hline & Latency (ms) & $407.130 \pm 39.851$ & $404.942 \pm 38.794$ & $408.531 \pm 37.379$ & $411.034 \pm 38.426$ & 1.465 & 0.003 & 0.574 \\
\hline \multirow[t]{2}{*}{ N1 } & Amplitude $(\mu \mathrm{V})$ & $-1.777 \pm 1.669$ & $-2.436 \pm 1.991$ & $-2.656 \pm 2.267$ & $-2.131 \pm 1.951$ & 1.042 & 0.056 & $4.434^{*}$ \\
\hline & Latency (ms) & $107.106 \pm 30.395$ & $112.700 \pm 30.348$ & $112.058 \pm 30.020$ & $111.097 \pm 33.639$ & 0.212 & 0.406 & 0.812 \\
\hline \multirow[t]{2}{*}{ P2 } & Amplitude $(\mu \mathrm{V})$ & $2.926 \pm 2.128$ & $1.915 \pm 1.588$ & $2.551 \pm 2.366$ & $3.084 \pm 3.041$ & 3.043 & 1.101 & $11.518^{* *}$ \\
\hline & Latency (ms) & $196.391 \pm 39.526$ & $193.541 \pm 36.700$ & $192.966 \pm 35.580$ & $190.720 \pm 38.724$ & 0.560 & 0.373 & 0.005 \\
\hline \multirow[t]{2}{*}{ N2 } & Amplitude $(\mu \mathrm{V})$ & $-0.864 \pm 2.284$ & $-1.511 \pm 1.868$ & $-1.261 \pm 2.380$ & $-0.919 \pm 2.590$ & 0.104 & 0.254 & 2.676 \\
\hline & Latency (ms) & $281.449 \pm 38.000$ & $287.420 \pm 32.518$ & $287.444 \pm 36.686$ & $283.198 \pm 35.468$ & 0.066 & 0.063 & 2.203 \\
\hline
\end{tabular}




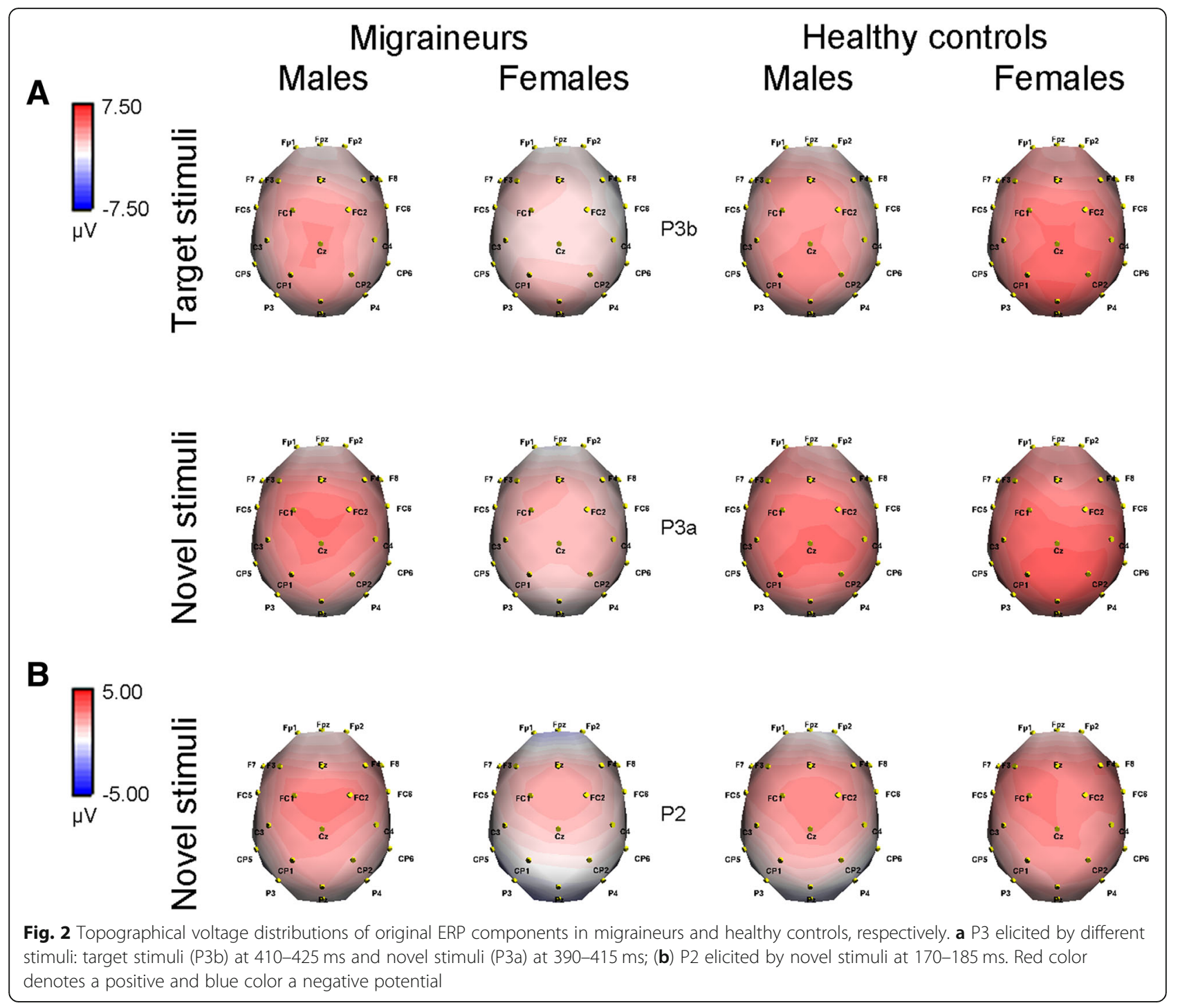

$(F(1,88)=2.749, p=0.101)$. By contrast, the amplitude was lower in female migraineurs in comparison with male migraineurs $(F(1,88)=9.871, p=0.002$, partial $\eta^{2}=0.101$ ) (see Fig. 2b for novel-elicited P2).

As for P2 latency, the electrode effect was proved remarkable $(F(1.768,155.604)=34.315, p<0.001$, partial $\left.\eta^{2}=0.281\right)$. Other effects or interactions were not significant $(p s>0.4)$.

\section{N2 component}

Neither group ( $p=0.748$ for amplitude; $p=0.797$ for latency) nor gender effects ( $p=0.615$ for amplitude; $p=0.803$ for latency) was found significant in $\mathrm{N} 2$ analysis. No group $\times$ gender interactions $(p=0.105$ for amplitude; $p=0.141$ for latency) was obtained either.

\section{Difference ERP analysis}

The difference waveforms are displayed in Fig. 3, in which P3 and P2 difference components were further analyzed (see Table 4 and Fig. 4).

\section{P $3 d_{T}$ and $P 3 d_{N}$ components}

The analysis of $P 3 d_{T}$ and $P 3 d_{N}$ (i.e., the P3 target and novel effects, respectively) amplitudes both demonstrated significant electrode effects $(F(1.976,173.868)=$

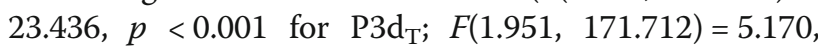
$p=0.007$ for $\left.\mathrm{P} \mathrm{d}_{\mathrm{N}}\right)$. The amplitudes were smaller for migraineurs $\quad\left(\mathrm{P}_{\mathrm{T}} \mathrm{d}_{\mathrm{T}}: 4.073 \pm 2.183 \mu \mathrm{V}, \quad \mathrm{P} 3 \mathrm{~d}_{\mathrm{N}}: 4.696 \pm\right.$ $2.082 \mu \mathrm{V})$ than for controls $\left(\mathrm{P}_{\mathrm{T}} \mathrm{d}: 6.033 \pm 3.497 \mu \mathrm{V}\right.$, $\mathrm{P}^{2} \mathrm{~d}_{\mathrm{N}}: 6.619 \pm 2.872 \mu \mathrm{V} ; p<0.001$, partial $\eta^{2}=0.187$ for $\mathrm{P} 3 \mathrm{~d}_{\mathrm{T}} ; p<0.001$, partial $\eta^{2}=230$ for $\mathrm{P} 3 \mathrm{~d}_{\mathrm{N}}$ ). We failed to find gender effects $(p s>0.1)$, while the significant interactions of group $\times$ gender $(p=0.003$, 


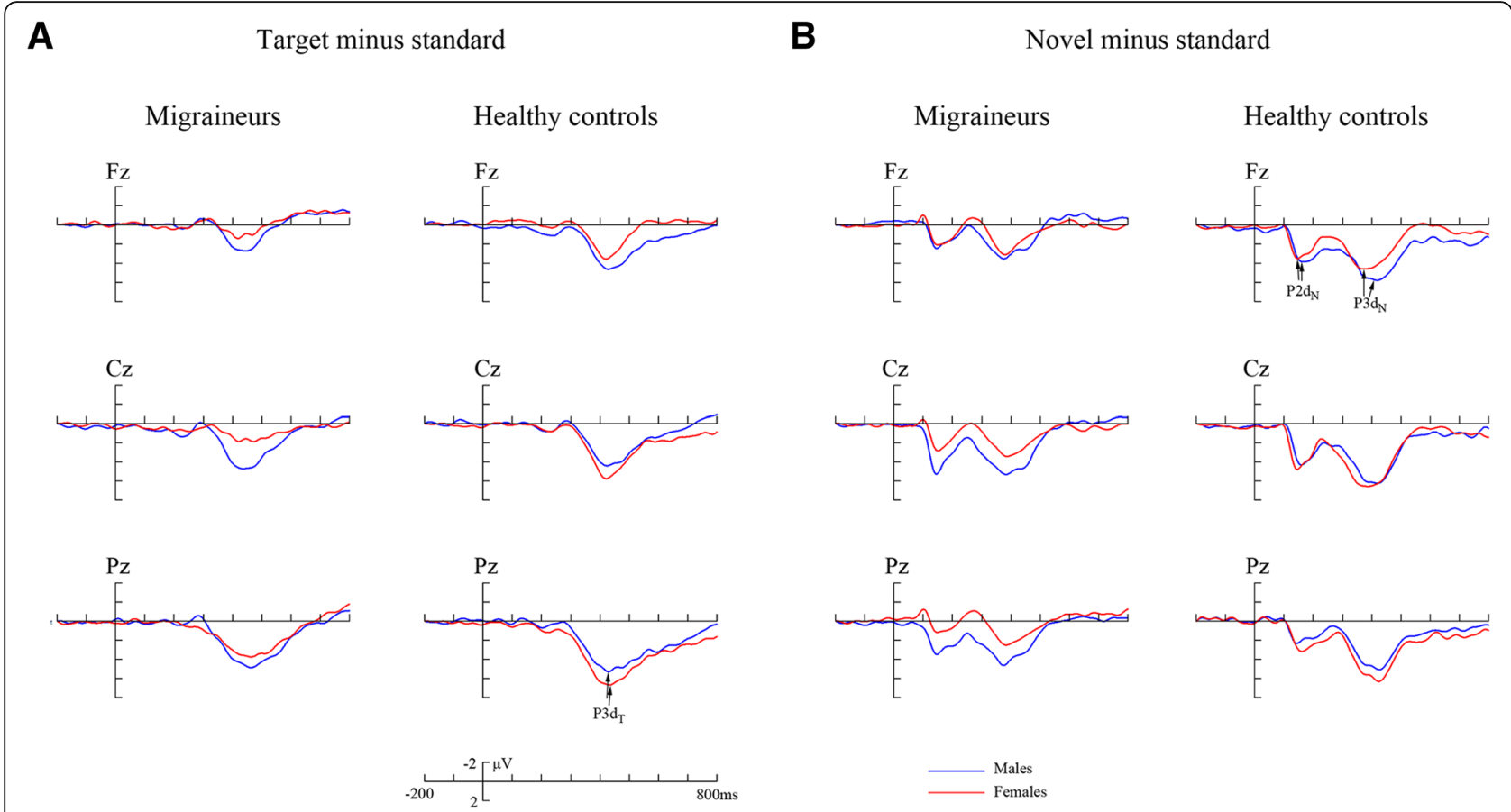

Fig. 3 The averaged difference waveforms in migraineurs and healthy controls at Fz, Cz and Pz, respectively. a Target minus standard difference ERPs; (b) novel minus standard difference ERPs. P3 $\mathrm{d}_{T}, \mathrm{P} 3 \mathrm{~d}_{\mathrm{N}}$ and P2 $\mathrm{d}_{\mathrm{N}}$ represent the P3 target effect, P3 and P2 novel effects, respectively. Blue line represents males and red line females

partial $\eta^{2}=0.095$ for $\mathrm{P} 3 \mathrm{~d}_{\mathrm{T}} ; p=0.001$, partial $\eta^{2}=$ 0.111 for $\mathrm{P}^{3} \mathrm{~d}_{\mathrm{N}}$ ) were observed (Table 4). Further comparisons suggested that in females, migraineurs exhibited reduced amplitudes $(F(1,88)=28.371, p<$ 0.001, partial $\eta^{2}=0.244$ for $\mathrm{P}^{2} \mathrm{~d}_{\mathrm{T}} ; F(1,88)=35.629$, $p<0.001$, partial $\eta^{2}=0.288$ for $\mathrm{P} 3 \mathrm{~d}_{\mathrm{N}}$ ), but not for males $(p s>0.2)$. Moreover, the amplitudes were remarkably affected by gender in patient group $(F(1,88)$ $=10.278, p=0.002$, partial $\eta^{2}=0.105$ for $\mathrm{P}^{2} \mathrm{~d}_{\mathrm{T}}$; $F(1,88)=11.778, \quad p=0.001$, partial $\eta^{2}=0.118$ for $\mathrm{P} 3 \mathrm{~d}_{\mathrm{N}}$ ), while not in control group ( $p s>0.2$ ) (Figs. 3a, b, $4 a$ and $b$ ).

No statistically significant difference was obtained in latencies of $\mathrm{P} 3 \mathrm{~d}_{\mathrm{T}}$ and $\mathrm{P} 3 \mathrm{~d}_{\mathrm{N}}(p \mathrm{~s}>0.05)$.

\section{P2 $\mathrm{d}_{\mathrm{N}}$ component}

The $\mathrm{P}^{2} \mathrm{~d}_{\mathrm{T}}$ (target minus standard) amplitude of participants did not differ significantly from zero in all electrodes (all $p>0.05$ by paired $t$-test) (Fig. 3a), thus only $\mathrm{P}^{2} \mathrm{~d}_{\mathrm{N}}$ (novel minus standard) was measured and analyzed. Although there was no difference between genders $(p=0.164)$ in $\mathrm{P}_{2} \mathrm{~d}_{\mathrm{N}}$ amplitude, the group effect $\left(p=0.012\right.$, partial $\left.\eta^{2}=0.070\right)$ and group $\times$ gender interaction $\left(p=0.004\right.$, partial $\left.\eta^{2}=0.089\right)$ were observed (see Table 4). Post-hoc tests revealed remarkable differences between female migraineurs and female controls $\left(F(1,88)=15.227, p<0.001\right.$, partial $\left.\eta^{2}=0.148\right)$, as well as between female migraineurs and male migraineurs $\left(F(1,88)=9.444, p=0.003\right.$, partial $\left.\eta^{2}=0.097\right)$. Other

Table 4 Results and analyses of difference ERP components

\begin{tabular}{|c|c|c|c|c|c|c|c|c|}
\hline \multirow[b]{2}{*}{ Difference ERPs } & & \multicolumn{2}{|l|}{ Migraineurs } & \multicolumn{2}{|l|}{ Healthy controls } & \multicolumn{3}{|l|}{ Statistics } \\
\hline & & Males & Females & Males & Females & $\begin{array}{l}\text { Group } \\
F(1,88)\end{array}$ & $\begin{array}{l}\text { Gender } \\
F(1,88)\end{array}$ & $\begin{array}{l}\text { Group } \times \text { Gender } \\
F(1,88)\end{array}$ \\
\hline \multirow[t]{2}{*}{$P 3 d_{T}$} & Amplitude $(\mu \mathrm{V})$ & $5.061 \pm 2.200$ & $3.086 \pm 1.668$ & $5.698 \pm 3.109$ & $6.367 \pm 3.840$ & $20.225^{* * *}$ & 2.245 & $9.215^{* *}$ \\
\hline & Latency (ms) & $428.406 \pm 34.649$ & $417.841 \pm 39.290$ & $423.594 \pm 37.222$ & $415.478 \pm 36.722$ & 0.407 & 2.760 & 0.047 \\
\hline \multirow[t]{2}{*}{$P 3 d_{N}$} & Amplitude $(\mu \mathrm{V})$ & $5.606 \pm 2.007$ & $3.787 \pm 1.740$ & $6.288 \pm 2.137$ & $6.950 \pm 3.440$ & $26.334^{* * *}$ & 2.383 & $10.955^{* *}$ \\
\hline & Latency (ms) & $387.754 \pm 36.008$ & $395.580 \pm 35.748$ & $396.464 \pm 32.580$ & $384.058 \pm 38.505$ & 0.056 & 0.148 & 2.890 \\
\hline \multirow[t]{2}{*}{$P 2 d_{N}$} & Amplitude $(\mu \mathrm{V})$ & $4.529 \pm 2.628$ & $3.072 \pm 2.208$ & $4.407 \pm 2.283$ & $4.922 \pm 2.651$ & $6.643^{*}$ & 1.974 & $8.650^{* *}$ \\
\hline & Latency (ms) & $165.362 \pm 34.496$ & $162.971 \pm 32.135$ & $176.594 \pm 35.897$ & $170.522 \pm 37.271$ & 2.867 & 0.582 & 0.110 \\
\hline
\end{tabular}

Data were expressed as mean \pm SD

P3 $d_{T}, P 3 d_{N}$ and P2 $d_{N}$ represent the P3 target effect (target minus standard), P3 and P2 novel effects (novel minus standard), respectively

${ }^{*} P<0.05$, ${ }^{* *} P<0.01,{ }^{* * *} P<0.001$ by repeated-measures ANOVA (Bonferroni correction) 


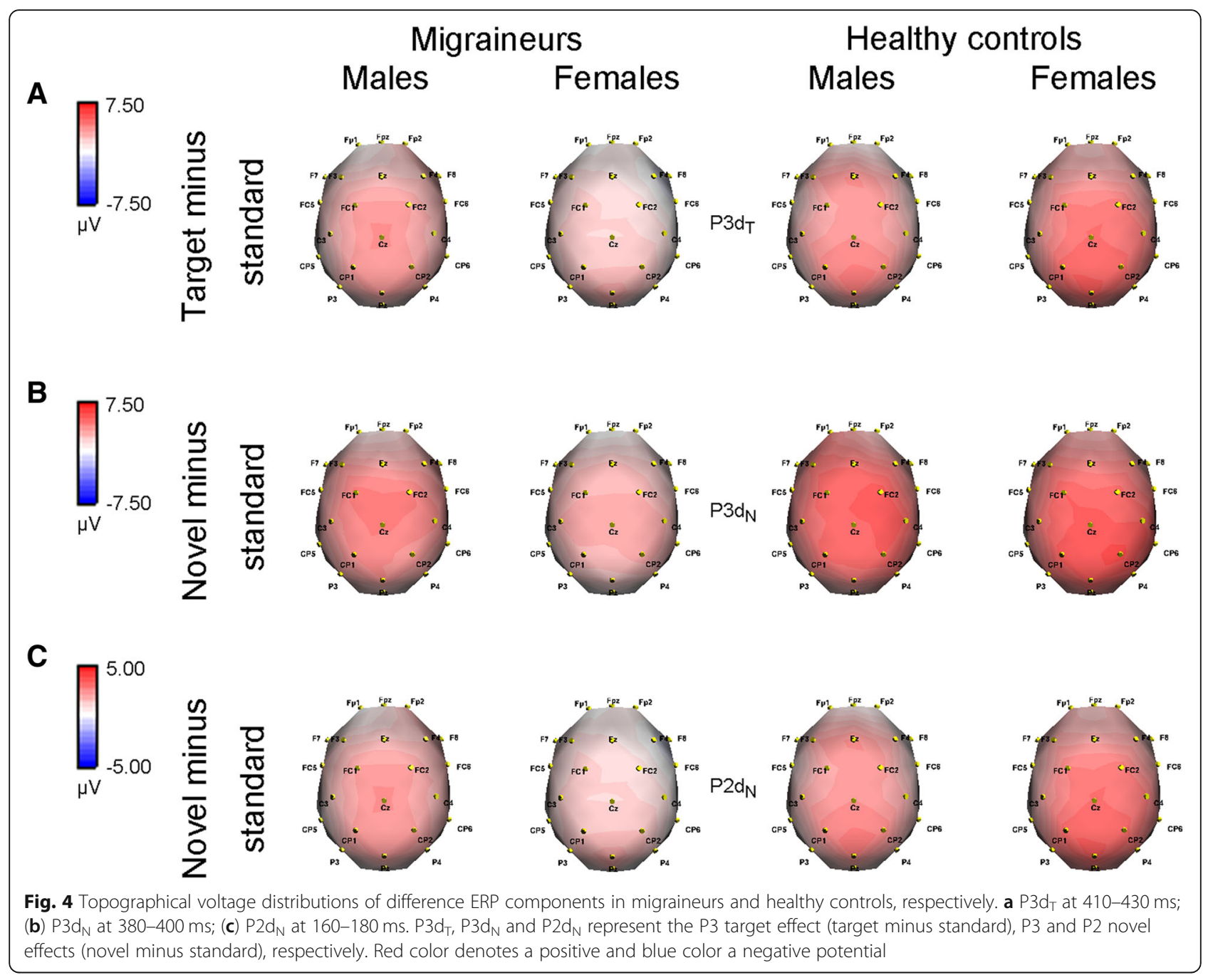

comparisons did not reach significant levels $(p s>0.2)$ (Figs. $3 \mathrm{~b}$ and $4 \mathrm{c}$ ).

We did not discover any notable effects or interactions in P2d $\mathrm{d}_{\mathrm{N}}$ latency $(p s>0.05)$.

\section{Discussion}

In the present study, by using a modified visual oddball paradigm, we discovered emotional and interictal attentive processing abnormalities in migraineurs, including higher levels of anxiety, reduced $\mathrm{P} 3, \mathrm{P} 3 \mathrm{~d}_{\mathrm{T}}$ and $\mathrm{P} 3 \mathrm{~d}_{\mathrm{N}}$ amplitudes, and lower $\mathrm{P} 2 \mathrm{~d}_{\mathrm{N}}$ amplitudes. Moreover, gender-related differences of these parameters in migraine patients were also observed, and female patients tended to suffer from more severe abnormalities in these domains compared with male patients, such as anxiety state, targeting processing and attention orienting [26].

Investigations in adults have established a correlation between migraine and internalizing psychiatric comorbidities [27]. Evaluated by emotional rating scales, although no discrepancy was obtained in SDS analysis, migraineurs reported higher scores on SAS, which was consistent with a previous study using same measurement scales [28]. More important was the phenomenon that female patients were more anxious than male patients, while this sex-related difference did not exist in healthy participants. Similarly, Juang et al. discovered that psychiatric disorders were more frequent in female patients with transformed migraine in comparison with male counterparts [29], and Wilcox et al. also reported a significant female predominance in comorbid anxiety in a recent cohort of 187 adolescents suffering from migraine [30]. Since anxiety and other mood disorders have been shown to be related to higher healthcare expenditures [31], poor quality of life [32] and even increased suicidal risk for migraineurs [33], as well as influencing their symptomology, clinical course and treatment response [34], it is reasonable to conclude that psychiatric comorbidities could lead to increased burdens as mentioned above, and to some extent, affecting clinical outcomes of migraine patients, such as perceived 
disability [35] and migraine chronification [36], particularly for women who seemed to have higher levels of anxiety.

$\mathrm{P} 3$, including $\mathrm{P} 3 \mathrm{~b}$ and $\mathrm{P} 3 \mathrm{a}$, is a generic name of various relatively late and positive components [21]. This reliable component is considered as mirroring aspects of cognitive processing, with its amplitude widely used as a measure of processing capacity and largely determined by attention allocation, working memory and decision making [37]. In this study, we discovered significant group effects in amplitudes of P3 and difference P3 components, indicating impaired cognitive processing of visual information in migraineurs overall. Consistently, other researchers found reduced P3 amplitude in migraine patients as well [38, 39]. Following analysis revealed significant difference between female patients and female controls, but not for male subjects. Interestingly, compared with male patients, lower amplitude was observed in female patients after controlling for age, education and other clinical characteristics. This disease-specific finding was further validated in $\mathrm{P}_{3} \mathrm{~d}_{\mathrm{T}}$ and $\mathrm{P} 3 \mathrm{~d}_{\mathrm{N}}$ components, which are believed to better represent attention and response towards task-relevant and deviant stimuli. The aforementioned results suggested that female patients might suffer from more severe abnormalities in visual neurocognitive processing under attentional conditions, such as target processing and attention orienting, at least in the interictal period.

P2, a cognitive-evaluative component with a predominant frontal distribution at around $200 \mathrm{~ms}$ post-stimulus, is indicative of early perceptual processing, feature detection, automatic evaluation and attentional recruitment $[40,41]$. Considering that the frontal region is crucial for these processes, P2 component could be employed to reflect frontal activity. Nevertheless, we failed to observe conspicuous $\mathrm{P} 2 \mathrm{~d}_{\mathrm{T}}$ due to a subset of participants displaying a difference "negativity", regardless of groups or genders. This subset of subjects did not differ in any characteristics from the other tested subjects. Although group effect was not found for P2 in original waveforms, it existed in difference $\mathrm{P} 2 \mathrm{~d}_{\mathrm{N}}$ amplitude, implying potential frontal dysfunction in migraine sufferers, which was verified in previous researches [7, 42]. In addition, similar sex discrepancies resembling P3 were also obtained in patients, suggesting that female migraineurs might have more serious disturbances in allocating attentional resources for the later cognitive processing than males did.

There are some pieces of indirect evidence supporting our observations. It was demonstrated that female patients suffering from chronic migraine showed more dysfunctional organization in resting functional networks than in male patients [17], and resting networks could be conceived as neurocognitive entities that incorporate both local and global processes [43]. Furthermore, Kruit et al. reported that women, but not men, with migraine with and without aura were at increased risk of high deep white matter lesion load [44]. Additionally, Palm-Meinders et al. discovered that female sufferers had a higher prevalence and a greater increase of deep white matter hyperintensities at the 9 -year follow up [45], and white matter hyperintensities as well as other structural abnormalities have been linked to multi-domain cognitive impairment in migraineurs and the elderly $[9,46]$. However, larger amplitudes of N2 and N2d (target minus standard) were obtained in male patients than female patients using an auditory oddball paradigm [38], which were not found in our study. The inconsistencies might arise from different stimuli used for ERP elicitation and distinct criteria for participant selection. So different paradigms and standardized experimental procedures should be used in future studies. More importantly, since migraine is known to be a multifactorial disorder, it is possible that the observed sex differences in cognitive processing might be affected by various determinants, including sex hormone fluctuations and genetic variance [11, 16], while the exact mechanisms deserve further elucidation.

To the best of our knowledge, this was the first study to report gender-related differences in neurocognitive processing of visual stimuli and topographical voltage distributions for migraineurs. A sensitive three-stimulus paradigm and difference waveforms were employed to make the results more convincing. Besides, sex discrepancies in emotional characteristics were investigated, and the effect of emotion on cognitive ERPs was almost ruled out (Pearson's correlations, see Additional file 1: Table S1). However, our study had several limitations when interpreting the present findings. Firstly, the small cohort did not include migraine patients with aura, which needed further investigation. Moreover, we recruited participants with broader age range, thus making the data less homogenate and resulting in lower statistical power. Finally, source analysis was not performed in this experiment, which we wished to work on in the near future to reveal neural generators of corresponding ERP components, and more microscopically, uncover possible gender-specific differences at the network level.

\section{Conclusions}

The present study revealed gender-related differences in interictal migraine patients without aura. We observed that the emotion and attentive visual processing of females seemed to be more vulnerable to migraine, for example, higher anxiety levels and lower amplitudes of cognitive original/difference ERP components. Our findings suggest the existence of gender effect and the importance of considering gender when investigating 
neurocognitive processing of migraineurs. In addition, it was demonstrated that migraine patients overall suffered from attentive processing abnormalities, which showed a skewed balance between males and females. Given this, in order to facilitate better outcomes for patients, it is important to highlight cognitive-behavioral therapy, and sex should also be taken into account, especially for women whose abnormalities tended to be more severe, at least indicated by this study. Moreover, in order to better understand gender-related discrepancies of migraine and their diverse mechanisms, more investigations are still warranted. Cognitive ERP components, such as P3, might serve as promising electrophysiological biomarkers to investigate gender-related differences of migraine in specific domains, while the availability needs to be further validated.

\section{Additional file}

Additional file 1: Table S1. Correlations between ERP data and emotional characteristics in migraineurs. (DOCX $19 \mathrm{~kb}$ )

\section{Abbreviations}

ANOVA: Analysis of variance; EEG: Electroencephalogram;

EOG: Electrooculogram; ERP: Event-related potential; ICA: Independent component analysis; ICHD-3 beta: Beta version of the International Classification of Headache Disorders, 3rd edition; P2 $d_{N}$ : P2 novel effect (novel minus standard); $P 2 d_{T}$ : P2 target effect (target minus standard); P3 $d_{N}$ : P3 novel effect (novel minus standard); P3d $\mathrm{d}_{\mathrm{T}}$ P3 target effect (target minus standard); SAS: Self-Rating Anxiety Scale; SD: Standard deviation; SDS: SelfRating Depression Scale; VAS: Visual analog scale; $\eta^{2}$ : Partial eta squared

\section{Acknowledgements}

We would like to thank all patients and healthy controls who took part in this study. We also thanked Jing Zhang, Department of Neurology (Shandong Provincial Hospital Affliated to Shandong University, Shandong, China) for helping to revise the manuscript to conform to submission requirements.

\section{Funding}

This research received no specific grant from any funding agency in the public, commercial, or not-for-profit sectors.

\section{Availability of data and materials}

The data supporting the conclusions of this article are held electronically in Department of Senile Neurology, Shandong Provincial Hospital Affiliated to Shandong University, Shandong, China. They are still being analyzed for further publications. These data will be made publicly available finally, and some of them can be obtained upon request to the corresponding author now.

\section{Authors' contributions}

YG, SX, SN, MH, YZ, JC, XH and YH carried out the studies. YG took part in the study design, preprocessed and measured EEG data, performed the statistical analysis and drafted the manuscript. SX, SN, MH and YZ helped to record subjects and measure data. Professor XL participated in the experimental design, subject recruitment, discussion of results, and manuscript revision. All authors read and approved this final manuscript submitted.

\section{Ethics approval and consent to participate}

The study protocol was approved by the Ethical Committee of Shandong Provincial Hospital Affiliated to Shandong University (Approval No. 2018215), which met the criteria of the Helsinki accord for experimentation of pain in human subjects. All participants gave their written and informed consent prior to the test.
Consent for publication

Not applicable.

\section{Competing interests}

The authors declare that they have no completing interests.

\section{Publisher's Note}

Springer Nature remains neutral with regard to jurisdictional claims in published maps and institutional affiliations.

\section{Author details}

${ }^{1}$ Department of Senile Neurology, Shandong Provincial Hospital Affiliated to Shandong University, Jinan 250021, Shandong, People's Republic of China. ${ }^{2}$ Anti-Aging Monitoring Laboratory, Shandong Provincial Hospital Affiliated to Shandong University, Jinan 250021, Shandong, People's Republic of China. ${ }^{3}$ Department of Anti-Aging, Shandong Provincial Hospital Affiliated to Shandong University, Jinan 250021, Shandong, People's Republic of China.

Received: 4 December 2018 Accepted: 12 April 2019

Published online: 23 April 2019

\section{References}

1. Terwindt GM, Ferrari MD, Tijhuis M, Groenen SM, Picavet HS, Launer LJ (2000) The impact of migraine on quality of life in the general population: the GEM study. Neurology 55:624-629

2. Ligthart L, Gerrits MM, Boomsma Dl, Penninx BW (2013) Anxiety and depression are associated with migraine and pain in general: an investigation of the interrelationships. J Pain 14:363-370

3. Serafini G, Pompili M, Innamorati M, Gentile G, Borro M, Lamis DA, Lala N, Negro A, Simmaco M, Girardi P, Martelletti P (2012) Gene variants with suicidal risk in a sample of subjects with chronic migraine and affective temperamental dysregulation. Eur Rev Med Pharmacol Sci 16:1389-1398

4. Coleston DM, Chronicle E, Ruddock KH, Kennard C (1994) Precortical dysfunction of spatial and temporal visual processing in migraine. J Neurol Neurosurg Psychiatry 57:1208-1211

5. Koppen H, Palm-Meinders I, Kruit M, Lim V, Nugroho A, Westhof I, Terwindt G, Van Buchem M, Ferrari M, Hommel B (2011) The impact of a migraine attack and its after-effects on perceptual organization, attention, and working memory. Cephalalgia 31:1419-1427

6. Chuang CS, Lin CL, Lin MC, Sung FC, Kao CH (2013) Migraine and risk of dementia: a nationwide retrospective cohort study. Neuroepidemiology 41: 139-145

7. Jia Z, Yu S (2017) Grey matter alterations in migraine: a systematic review and meta-analysis. Neuroimage Clin 14:130-140

8. Kruit MC, Van Buchem MA, Launer LJ, Terwindt GM, Ferrari MD (2010) Migraine is associated with an increased risk of deep white matter lesions, subclinical posterior circulation infarcts and brain iron accumulation: the population-based MRI CAMERA study. Cephalalgia 30:129-136

9. Rist PM, Kurth T (2013) Migraine and cognitive decline: a topical review. Headache 53:589-598

10. Yu S, Liu R, Zhao G, Yang X, Qiao X, Feng J, Fang Y, Cao X, He M, Steiner T (2012) The prevalence and burden of primary headaches in China: a population-based door-to-door survey. Headache 52:582-591

11. Vetvik KG, Macgregor EA (2017) Sex differences in the epidemiology, clinical features, and pathophysiology of migraine. Lancet Neurol 16:76-87

12. Le H, Tfelt-Hansen P, Russell MB, Skytthe A, Kyvik KO, Olesen J (2011) Comorbidity of migraine with somatic disease in a large population-based study. Cephalalgia 31:43-64

13. Tietjen GE, Herial NA, Hardgrove J, Utley C, White L (2007) Migraine comorbidity constellations. Headache 47:857-865

14. Buse DC, Loder EW, Gorman JA, Stewart WF, Reed ML, Fanning KM, Serrano D, Lipton RB (2013) Sex differences in the prevalence, symptoms, and associated features of migraine, probable migraine and other severe headache: results of the American Migraine Prevalence and Prevention (AMPP) study. Headache 53:1278-1299

15. Ferrari A, Tiraferri I, Neri L, Sternieri E (2011) Why pharmacokinetic differences among oral triptans have little clinical importance: a comment. J Headache Pain 12:5-12

16. Brandes $J \mathrm{~L}$ (2006) The influence of estrogen on migraine: a systematic review. JAMA 295:1824-1830 
17. Liu J, Qin W, Nan J, Li J, Yuan K, Zhao L, Zeng F, Sun J, Yu D, Dong M, Liu P, Von Deneen KM, Gong Q, Liang F, Tian J (2011) Gender-related differences in the dysfunctional resting networks of migraine suffers. PLoS One 6:e27049

18. Maleki N, Linnman C, Brawn J, Burstein R, Becerra L, Borsook D (2012) Her versus his migraine: multiple sex differences in brain function and structure. Brain 135:2546-2559

19. Yuan J, He Y, Qinglin Z, Chen A, Li H (2008) Gender differences in behavioral inhibitory control: ERP evidence from a two-choice oddball task. Psychophysiology 45:986-993

20. Miller DI, Halpern DF (2014) The new science of cognitive sex differences. Trends Cogn Sci 18:37-45

21. Polich J (2007) Updating P300: an integrative theory of P3a and P3b. Clin Neurophysiol 118:2128-2148

22. Han M, Hou X, Xu S, Hong Y, Chen J, Ma Y, Nie S, Liu X (2019) Selective attention network impairment during the interictal period of migraine without aura. J Clin Neurosci 60:73-78

23. Zung WW (1971) A rating instrument for anxiety disorders. Psychosomatics 12:371-379

24. Zung WW (1965) A self-rating depression scale. Arch Gen Psychiatry 12:63-70

25. Jung TP, Makeig S, Humphries C, Lee TW, Mckeown MJ, Iragui V, Sejnowski TJ (2000) Removing electroencephalographic artifacts by blind source separation. Psychophysiology 37:163-178

26. Polich J, Kok A (1995) Cognitive and biological determinants of P300: an integrative review. Biol Psychol 41:103-146

27. Radat F, Swendsen J (2005) Psychiatric comorbidity in migraine: a review. Cephalalgia 25:165-178

28. Huang L, Juan Dong H, Wang $X$, Wang Y, Xiao Z (2017) Duration and frequency of migraines affect cognitive function: evidence from neuropsychological tests and event-related potentials. J Headache Pain 18:54

29. Juang KD, Wang SJ, Fuh JL, Lu SR, Su TP (2000) Comorbidity of depressive and anxiety disorders in chronic daily headache and its subtypes. Headache 40:818-823

30. Wilcox SL, Ludwick AM, Lebel A, Borsook D (2018) Age- and sex-related differences in the presentation of paediatric migraine: a retrospective cohort study. Cephalalgia 38:1107-1118

31. Lucchetti G, Peres MF, Lucchetti AL, Mercante JP, Guendler VZ, Zukerman E (2013) Generalized anxiety disorder, subthreshold anxiety and anxiety symptoms in primary headache. Psychiatry Clin Neurosci 67:41-49

32. Lipton RB, Hamelsky SW, Kolodner KB, Steiner TJ, Stewart WF (2000) Migraine, quality of life, and depression: a population-based case-control study. Neurology 55:629-635

33. Breslau N, Davis GC, Andreski P (1991) Migraine, psychiatric disorders, and suicide attempts: an epidemiologic study of young adults. Psychiatry Res 37: $11-23$

34. Louter MA, Pijpers JA, Wardenaar KJ, Van Zwet EW, Van Hemert AM, Zitman FG, Ferrari MD, Penninx BW, Terwindt GM (2015) Symptom dimensions of affective disorders in migraine patients. J Psychosom Res 79:458-463

35. Innamorati M, Pompili M, Fiorillo M, Lala N, Negro A, Del Bono SD, Lester D, Girardi P, Martelletti P (2013) Overattachment and perceived disability in chronic migraineurs. Clin Neurol Neurosurg 115:954-958

36. Buse DC, Silberstein SD, Manack AN, Papapetropoulos S, Lipton RB (2013) Psychiatric comorbidities of episodic and chronic migraine. J Neurol 260: 1960-1969

37. Kok A (2001) On the utility of P3 amplitude as a measure of processing capacity. Psychophysiology 38:557-577

38. Wang R, Dong Z, Chen X, Zhang M, Yang F, Zhang X, Jia W, Yu S (2014) Gender differences of cognitive function in migraine patients: evidence from event-related potentials using the oddball paradigm. J Headache Pain 15:6

39. Chen W, Shen X, Liu X, Luo B, Liu Y, Yu R, Sun G, Shen M, Wang W (2007) Passive paradigm single-tone elicited ERPs in tension-type headaches and migraine. Cephalalgia 27:139-144

40. Chen A, Xu P, Wang Q, Luo Y, Yuan J, Yao D, Li H (2008) The timing of cognitive control in partially incongruent categorization. Hum Brain Mapp 29:1028-1039

41. Carretie L, Mercado F, Tapia M, Hinojosa JA (2001) Emotion, attention, and the 'negativity bias', studied through event-related potentials. Int $J$ Psychophysiol 41:75-85

42. Schmitz N, Arkink EB, Mulder M, Rubia K, Admiraal-Behloul F, Schoonman GG, Kruit MC, Ferrari MD, Van Buchem MA (2008) Frontal lobe structure and executive function in migraine patients. Neurosci Lett 440:92-96
43. Fox MD, Raichle ME (2007) Spontaneous fluctuations in brain activity observed with functional magnetic resonance imaging. Nat Rev Neurosci 8: $700-711$

44. Kruit MC, Van Buchem MA, Hofman PA, Bakkers JT, Terwindt GM, Ferrari MD, Launer $L J$ (2004) Migraine as a risk factor for subclinical brain lesions. JAMA 291:427-434

45. Palm-Meinders $\mathbb{H}_{\text {, Koppen }} \mathrm{H}$, Terwindt $\mathrm{GM}$, Launer $\amalg$, Konishi J, Moonen JM, Bakkers JT, Hofman PA, Van Lew B, Middelkoop HA, Van Buchem MA, Ferrari MD, Kruit MC (2012) Structural brain changes in migraine. JAMA 308: 1889-1897

46. Van Der Flier WM, Van Straaten EC, Barkhof F, Verdelho A, Madureira S, Pantoni L, Inzitari D, Erkinjuntti T, Crisby M, Waldemar G, Schmidt R, Fazekas F, Scheltens P (2005) Small vessel disease and general cognitive function in nondisabled elderly: the LADIS study. Stroke 36:2116-2120
Ready to submit your research? Choose BMC and benefit from:

- fast, convenient online submission

- thorough peer review by experienced researchers in your field

- rapid publication on acceptance

- support for research data, including large and complex data types

- gold Open Access which fosters wider collaboration and increased citations

- maximum visibility for your research: over $100 \mathrm{M}$ website views per year

At BMC, research is always in progress.

Learn more biomedcentral.com/submissions 